\title{
Technology-Driven Responsiveness in Times of COVID-19: A Fuzzy Delphi and Fuzzy AHP-Based Approach
}

\author{
Chetna Chauhan $^{1}$ (D) Manzoor Ul Akram $^{2}$ (D) $\cdot$ Diptanshu Gaur $^{3}$ (D)
}

Received: 25 April 2021 / Accepted: 12 August 2021 / Published online: 23 September 2021

(c) Global Institute of Flexible Systems Management 2021

\begin{abstract}
Supply chain responsiveness creates value for firms and their stakeholders and is a key towards generating above-normal profits for firms. Consequently, there has been a surge of research on it, which has expanded due to the pressures to be responsive during the pandemic of COVID19. Responsiveness is an attribute wherein the supply chains are equipped to respond resolutely and within a suitable timeframe to consumer requirements. The trouble to businesses posed by COVID19 caught several firms off-guard. Further, there is limited research on the augmentation of supply chain responsiveness through new technologies. The present research, therefore, applies a hybrid approach by combining fuzzy Delphi and fuzzy AHP to understand the technology-driven enablers of supply chain responsiveness by employing a case company in food retail. The investigation reveals that supply chain integration technologies, sustainable manufacturing technologies, and smart warehousing are the most important enablers of supply chain responsiveness in the context of food supply chains. The results aid the key enablers that need attention and resources to be directed towards these enablers to eliminate a chance of missing on a successful transition into a more responsive supply chain.
\end{abstract}

Keywords Technological capability $\cdot$ Responsive supply chains $\cdot$ COVID-19 $\cdot$ Enablers

\section{Introduction}

The firms need to adjust and alter their operations speedily to survive and proficiently respond to numerous challenges in the environment (Deshmukh \& Haleem, 2020). For example, the COVID-19 outbreak has severely crippled several firms. The lockdown had an aggravating effect on the manufacturing and logistics activities of the firms, which in turn affected the demand and supply of various products (Singh et al., 2021). For example, in the case of food supply chains, the issues that have caught the attention of scholars and policymakers globally include changes in consumption patterns as well as the setup and workforce responsible for maintaining a safe and trustworthy food supply network (Deconinck et al., 2020; Singh et al., 2021). These issues were deemed

Chetna Chauhan

chetnayashi@gmail.com

1 Quantitative Techniques and Operations Management, FORE School of Management, New Delhi, India

2 O. P. Jindal Global University, Sonipat, India

3 Indian Institute of Management Rohtak, Rohtak, India serious as a pandemic is marked by the restrictions over movement, changes in demand patterns, shut down of food manufacturing units, changes in food trade policies, financial stress, and food safety concerns (Momaya, 2020).

Responsiveness of a firms' supply chain is critical for it to inspect and respond to the changes in customer behavior that can lead to supply chain variability (Yang et al., 2019). A responsive supply chain characterized by shorter lead times, small sizes of the batch, and fewer setup costs. All these factors permit the responsive company to adjust quickly to the changes in demand (Randall et al., 2003). Building responsiveness is seen as an essential approach to revive operations and supply chains in post-COVID-19 times (Frederico, 2021). Moreover, making supply chains responsive is seen as a successful strategy to compete globally (Gunasekaran et al., 2008). The pandemic has led to extraordinary disruptions in the supply chains across several sectors such as healthcare, food, engineering, and automotive, among others. In contrast to other disruptions, the current pandemic has affected all the stages of supply chains, with significant disturbance in manufacturing, logistics, along with substantial shifts in consumption patterns. The aim of developing responsive supply chains 
is to be better prepared for the execution of tasks during unexpected occurrences such as COVID-19.

While responsive supply chains form an integral part of successful manufacturing strategies, how to develop a responsive supply chain has been a pertinent question across the global production environments (Roh et al., 2014). Scholars have argued that firms can transform the traditional supply chains into more responsive ones through strategic actions (Godsell et al., 2006). To this end, the extant literature has argued that technology can pose solutions that can be utilized to enhance the responsiveness of the supply chains. For example, digitalization technologies boost the visibility of the supply chains, which in turn enhances real-time decision-making capability, which further leads to improved responsiveness (Yadav et al., 2020).

The realization of supply chain responsiveness is not reliant upon a few enabling forces but depends upon diverse enablers, frequently spanning firm boundaries. Scholars have argued that the seamless integration and coordination of various operations such as production, distribution, sourcing, and procurement with the help of centralized IT infrastructure can significantly raise overall supply chain responsiveness (Aftab et al., 2018). Therefore, in the paper, we provide a refined understanding of the technology-driven enablers from the perspective of the firms that are in the process of improving the responsiveness of their supply chains. The emergence of responsiveness is influenced by contingent factors faced by the firms that include the ongoing COVID19 crisis. Therefore, a contingency theory approach has been used as a theoretical lens for the present study. This study identifies critical enablers of responsiveness, which are driven by digitalization. The study underlines the enablers by referring to the literature and supplements them with the assistance of the opinion of experts. These enablers are then analyzed for the case of a firm that is undertaking a transition from conventional to responsive supply chains. Therefore, the present work seeks to answer the following research questions:

- What are the enablers that help the firms in their transition from traditional to responsive supply chains?

- How to establish the priority of these enablers that affect responsiveness?

To address the above research questions, set in the context of an example from the food supply chain, important enablers conveyed in the literature were enlisted through a comprehensive survey of the literature. The fuzzy Delphi technique is utilized to decide the finalization of identified enablers. Fuzzy AHP is used to establish the relative importance of these enablers. The fuzzy logic is applied since AHP is not adequate to manage the uncertainty and vagueness that is present in human judgments (Kumar et al., 2018).

The rest of the study is organized as follows. "Theoretical Background" gives an overview of the theoretical background of the study. The methodology of research is elucidated in "Research Methodology". The case application is discussed in "Case Description". In "Application of the Proposed Methodology to the Case", the proposed methodology is applied to the case. In "Discussion", the discussion of the results obtained from the analysis is presented. In "Conclusions", the study concludes with academic and managerial implications, limitations, as well as future research directions.

\section{Theoretical Background}

\section{Contingency Theory Perspective}

The operations management (OM) scholars have always emphasized the importance of understanding the relationship between the firm and the environment (Makkonen et al., 2014). The past two decades have witnessed a surge in the application of theories from domains such as strategic management and have immensely benefited the OM scholars. The contingency theorists emphasize that compatibility between the firm and the environment in which it operates is crucial for its performance. Therefore, the firms must adapt their structures by considering the environment to perform better.

Contingency theorists view the organization as an open system where information gets exchanged. The exchange of information happens through a system that comprises inputs, processes, and outputs. The contextual issues faced by the firm are together termed as the input. The responses to these inputs comprise strategies and actions and are termed as processes. The outcomes of the processes are termed output. The contingency theorists posit that the firms strive to find the best solutions to cope with contextual situations by utilizing their processes. As proposed by the contingency theory, when a firm faces contextual issues such as supply chain disruptions, it should devise strategies to cope with the same (McAdam et al., 2019). Proactive management of disruptions in the supply chain due to the pandemic can be managed with the help of technology capabilities specific to the firm's supply chain. The output of such a system can be enhanced decision-making for building a responsive supply chain.

The extant literature suggests that several factors play a crucial role in enhancing a firm's proactiveness towards managing supply chain disruptions (Grötsch et al., 2013). This is in accordance with contingency theory, which suggests that the internal and external situation of a firm decides 
the optimum course of action. In the present study, the outbreak of the pandemic can be understood as a major contingency, and the level of disruptions faced by the firms are major indicators of the contingent situation (Grötsch et al., 2013). For managing these disruptions, the firms need to build their technological capability proactively.

\section{Technological Capability and Supply Chain Responsiveness}

In particular, both researchers and practitioners endorse that greater visibility leads to better responsiveness (Williams et al., 2013). Supply chain integration gives additional access to information as well as processing abilities essential to incorporate responsiveness (Roh et al., 2014). The use of technology improves global supply chain relationships (Sinkovics et al., 2011) as an integrated value chain boosts buyer-supplier collaboration (Gunasekaran et al., 2008). The revolution in the supply chains with the help of digital technologies such as artificial intelligence (AI), big data, among others, are transforming the linear supply chains into integrated structures where information flows in an omnidirectional manner. These technologies can produce massive benefits through cost reduction and making supply chains more responsive to demand. Technology breakthroughs in supply chain strategies such as the ones brought by advanced production technologies and e-procurement increase supply chain responsiveness that helps the supply chains to react quickly against disruptions (Kim et al., 2013). An important component of a responsive supply chain is its capability to sense and respond to eliminate disruptions. Ongoing advances in technology can ease sensing through data collected in real-time (Gunasekaran et al., 2008). Several authors have contended that a data-driven supply chain has a positive effect on supply chain responsiveness (Ishtiaque et al., 2020; Yu et al., 2018). The application of predictive analytics includes identifying safety risks, predicting the sustainability performance of the supply chain, and evaluation of packaging material (Kamble et al., 2020).

Maintaining service levels with appropriate stocking has been widely seen as a strategy for supply chain responsiveness (Piprani et al., 2020). In this regard, several servicelevel related strategic initiatives can improve responsiveness (see Table 1). For instance, AI has helped food supply chains to reach the market very efficiently through better planning. Large amounts of food can be sorted by size, nutrients, constituents, shape, etc., and sent to customers (Di Vaio et al., 2020). Inventory has a considerable influence on responsiveness. Smart warehousing, order management, and retail management increase the chances of meeting demand by ensuring product availability at the right place and time (Riahi et al., 2021). These systems would be able to track the movement of goods automatically, thus monitoring the inventory in real-time. The service level is maintained by avoiding over or understocking (Riahi et al., 2021). AI also helps to identify factors responsible for failure in a process with its root cause analysis. It can be used to develop a realtime data system for maintaining the stock of products by utilizing a pre-warning approach (Kamble et al., 2020).

In addition, sustainability initiatives such as sustainable manufacturing, packaging, sourcing, and distribution have also been regarded as drivers of responsiveness. These practices reduce the generation of waste and promote effective resource utilization, thereby helping the firm to survive in the long-term survival of the firms (Katiyar et al., 2018). Sustainable practices also enhance the firm's control towards different processes, sustainable practices and are considered a crucial driver of the supply chain responsiveness (Van Der Vorst et al., 2009).

In light of the above several technology-driven enablers of supply chain responsiveness have been found out from the extant literature and been broadly typified under three dimensions, namely visibility, service, and sustainability, as shown in Table 1. The enablers shown in Table 1 will be utilized for achieving the objectives of the present research. The objectives are: (a) To develop an understanding of the enablers that help the firms in their transition from traditional to responsive supply chains? (b) To establish the priority of these enablers that affect responsiveness?

\section{Research Methodology}

\section{Fuzzy Delphi Method}

The fuzzy Delphi method is a systematic tool for forecasting. The method considers the judgment of the experts as crucial and is more often used in scenarios where a resolution for an issue is unavailable. The method simplifies the decisionmaking process by eliminating the less important variables (Bouzon et al., 2016). One of the drawbacks of the Delphi method was the collection of data in the form of repeated surveys that were more costly and time-consuming.

To overcome the drawbacks of the Delphi method, the fuzzy-based Delphi method was introduced by Ishikawa et al. (1993). To facilitate group decision-making, various researchers have used the fuzzy Delphi method in combination with fuzzy AHP. Fuzzy Delphi was applied by the panel to assess the consensus level of each enabler. The fuzzy Delphi approach helps to screen out the factors in the preliminary stage on the basis of consensus between experts before ranking is carried out (Gupta et al., 2021). For the study, we have considered fuzzy Delphi to enable group decision-making. It facilitated understanding the 
Table 1 Technology led enablers of supply chain responsiveness

\begin{tabular}{|c|c|c|c|}
\hline Dimension & Enabler & Description & Sample references \\
\hline \multirow[t]{6}{*}{ Visibility } & Supply chain integration technologies & $\begin{array}{l}\text { All those classes of technologies that integrate } \\
\text { the food supply chain upstream as well as } \\
\text { downstream }\end{array}$ & Li (2012) \\
\hline & RFID-based location tracking & $\begin{array}{l}\text { A no-contact automatic identification commu- } \\
\text { nication technology to tag, save and manage } \\
\text { information on products using radio frequency } \\
\text { signaling and associated tools }\end{array}$ & Pramatari et al. (2010) \\
\hline & Big data and cloud-based demand prediction & $\begin{array}{l}\text { Management and analysis of data characterized } \\
\text { by volume, variety, and velocity }\end{array}$ & Irani et al. (2018) \\
\hline & Smart warehousing & $\begin{array}{l}\text { A warehouse designed to perform at the highest } \\
\text { efficiency }\end{array}$ & Mahroof (2019) \\
\hline & Blockchain technology or traceability & $\begin{array}{l}\text { A distributed ledger technology (DLT) where } \\
\text { alterations are not permitted once data is } \\
\text { logged, becoming a trusted source of informa- } \\
\text { tion, enabling efficiency, transparency, and } \\
\text { accountability among participating actors }\end{array}$ & Stranieri et al. (2021) \\
\hline & Predictive analytics for resource optimization & $\begin{array}{l}\mathrm{AI} \text { is derived from data and has the potential to } \\
\text { transform industrial productivity }\end{array}$ & Kamble et al., (2020) \\
\hline \multirow[t]{6}{*}{ Service } & AI for supply network and monitoring & $\begin{array}{l}\text { AI is derived from data and has the potential to } \\
\text { transform industrial productivity }\end{array}$ & Di Vaio et al. (2020) \\
\hline & Smart logistics technologies & $\begin{array}{l}\text { Management of physical movement of goods } \\
\text { through smart tools and methods }\end{array}$ & (Rakyta et al. 2016) \\
\hline & Online transparent presence & $\begin{array}{l}\text { Transparency for stakeholders of food supply } \\
\text { chains through data and online management } \\
\text { of networks }\end{array}$ & Astill et al. (2019) \\
\hline & Smart retail technology & $\begin{array}{l}\text { Network of smart, intelligent systems engaging } \\
\text { in assimilating real-time data to deliver retail } \\
\text { services to consumers }\end{array}$ & Wuenderlich et al. (2015) \\
\hline & Smart order management technologies & $\begin{array}{l}\text { Planning and controlling of orders through } \\
\text { smart tools and analytics }\end{array}$ & Aung and Chang (2014) \\
\hline & Drone logistics & $\begin{array}{l}\text { Intelligent and unmanned technologies to } \\
\text { deliver food products }\end{array}$ & Sah et al. (2020) \\
\hline \multirow[t]{3}{*}{ Sustainability } & Sustainable sourcing and distribution & $\begin{array}{l}\text { Sustainability operations such as sustainable } \\
\text { sourcing and distribution }\end{array}$ & Acar et al. (2019) \\
\hline & Sustainable food packaging & $\begin{array}{l}\text { New and improved packaging that increases the } \\
\text { shelf-life of food products and decreases the } \\
\text { carbon footprint }\end{array}$ & Mikkonen and Tenkanen (2012) \\
\hline & Sustainable manufacturing technologies & $\begin{array}{l}\text { Technologies that improve sustainability, for } \\
\text { example, by minimizing waste, thereby reduc- } \\
\text { ing pressures on firms to manage the waste }\end{array}$ & Dubey et al. (2015) \\
\hline
\end{tabular}

enablers of supply chain responsiveness. The steps of the fuzzy Delphi method are as follows.

Step 1 The step involved the identification of different enablers of supply chain responsiveness. The enablers identified in the literature survey are given in Table 1.

Step 2 The enablers identified in the earlier step were examined by the industry experts. The judgment of the experts was captured with the help of the linguistic scale given in Table 2.

Let the $l$ th (where $l=1,2,3 \ldots m$ ) enabler evaluation of the $k$ th expert (where $k=1,2,3 \ldots n$ ) is the triangular fuzzy number $Y_{k l}$ :
Table 2 Linguistic scales

\begin{tabular}{ll}
\hline Linguistic variables & Fuzzy number \\
\hline Extremely low & $(0,0,0.1)$ \\
Very low & $(0,0.1,0.3)$ \\
Low & $(0.1,0.3,0.5)$ \\
Medium & $(0.3,0.5,0.7)$ \\
High & $(0.5,0.7,0.9)$ \\
Very high & $(0.7,0.9,1.0)$ \\
Extremely high & $(0.9,1.0,1.0)$ \\
\hline
\end{tabular}

$Y_{k l}=\left(\mathrm{M}_{k l}, N_{k l}, O_{k l}\right)$. 
The fuzzy weights of the enabler $P_{l}$ are computed as follows:

$P_{l}=\left(M_{l}, N_{l}, O_{l}\right)$,

$M_{l}=\min \left(M_{k l}\right)$,

$N_{l}=\left(\prod_{\mathrm{k}=1}^{n} N_{k l}\right)^{1 / n}$,

$O_{l}=\max \left(O_{k l}\right)$.

Step 3 The importance $\left(S_{l}\right)$ of each enabler is calculated by applying the mean method. The value $\alpha$ (threshold value) is set for selecting the enabler into the list which will be used as an input to fuzzy AHP. If the computed value of importance is lesser than $\alpha$, that enabler is not selected:

$S_{l}=\left(M_{l}+N_{l}+O_{l}\right) / 3$.

\section{Fuzzy AHP}

AHP was developed as an instrument for multi-criteria decision-making (MCDM) problems. AHP helps in simplifying a complex decision-making problem by disintegrating it into smaller problems (Saaty, 2008). It translates the problem of decision-making into a hierarchy that consists of a goal, criteria, and sub-criteria. AHP method is especially advantageous when different factors have different weights (Yadav et al., 2021). On the other hand, techniques such as ISM and DEMATEL are deemed useful to understand the hierarchical relationships among the factors. In this study, all enablers are being considered to have relative weightage. Due to the many benefits of Fuzzy AHP over other mathematical methods, many researchers have used these methods for handling complex decision-making problems. The AHP considers the judgments of the expert decisionmakers. However, it does not resolute the inaccuracy and ambiguity which is associated with human judgments (Chang, 1996). Fuzzy AHP, which is based on the fuzzy set theory. Numerous methods for fuzzifying the AHP process have been documented by scholars in the extant literature. Chang's extent-analysis-based method is one of the widely used approaches among them (Chauhan \& Singh, 2020). Chang's extent analysis relies upon the calculation of synthetic extent values of the fuzzy triangular number (FTN) (Chang, 1996). These values were based on pairwise comparisons. An extent analysis for each criterion concerning goal $q_{i}$ is conducted in this method. The extent-analysisbased tool is used to compute a set for satisfying the goal and this set is known as satisfying extent.

If $V=\left\{v_{1}, v_{2}, \ldots, v_{n}\right\}$ is set for criterion, and $Q=\left\{q_{1}, q_{2}, \ldots\right.$, $\left.q_{n}\right\}$ is set of goal, to apply Chang's method of extent analysis, an extent analysis is done on each enabler. ' $m$ ' values for extent analyses carried out on each enabler are calculated as follows:

$U_{g_{i}}^{1}, U_{g_{i}}^{2}, U_{g_{i}}^{3}, U_{g_{i}}^{4}, \ldots U_{g_{i}}^{m}, i=1,2,3 \ldots n$,

where $U_{g_{i}}^{j}(j=1,2,3 \ldots .4)$ are fuzzy triangular numbers (FTNs).

The steps are as follows:

Step 1 The fuzzy Delphi approach is applied to finalize the enablers, which are then evaluated by the experts on a linguistic scale (see Table 3). The linguistic inputs are then converted into FTNs. Buckley's geometric mean method (Buckley, 1985) is applied to calculate the elements of the pairwise comparison matrix, in combination with expert inputs.

Let there be ' $n$ ' enablers. The pairwise comparison of $i$ th enabler with $j$ th enabler will lead to the development of the fuzzy matrix $U_{n \times n}$. In the fuzzy square matrix, $\tilde{U}_{i j}$ signifies the relative importance of enabler $i$ with respect to enabler $j$. In the fuzzy square matrix, $\tilde{U}_{i j}=(1,1,1)$ if $i=j$ and $\tilde{U}_{j i}$ is the reciprocal of $\tilde{U}_{i j}$ :
Table 3 Membership function of linguistic scale

\begin{tabular}{lll}
\hline Intensity of importance & Linguistic & $\begin{array}{l}\text { Scale of } \\
\text { fuzzy num- } \\
\text { ber }\end{array}$ \\
\hline 9 & & $(8,9,10)$ \\
8 & Perfect & $(7,8,9)$ \\
7 & Absolute & $(6,7,8)$ \\
6 & Very good & $(5,6,7)$ \\
5 & Fairly good & $(4,5,6)$ \\
4 & Good & $(3,4,5)$ \\
3 & Preferable & $(2,3,4)$ \\
2 & Not bad & $(1,2,3)$ \\
1 & Weak advantage & $(1,1,1)$ \\
Reciprocal of above & Equal & If activity $i$ has one of these numbers assigned when compared with \\
& activity $j$, then $j$ will have the reciprocal value when compared & \\
\hline & with $i$ &
\end{tabular}




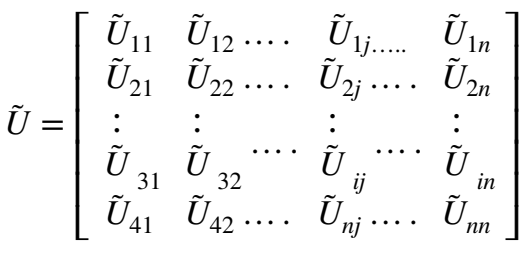

If the number of experts is $K$, components of pairwise comparison matrix are computed as follows:

$\tilde{U}_{i j}=\left(\tilde{U}_{i j}^{1} \otimes \tilde{U}_{i j}^{2} \otimes \tilde{U}_{i j}^{3} \otimes \tilde{U}_{i j}^{4} \otimes \tilde{U}_{i j}^{5} \otimes \ldots \tilde{U}_{i j}^{k}\right)^{1 / K}$.

Step 2 Estimate the fuzzy synthetic degree with respect to the $i$ th enabler using the following:

$F_{i}=\sum_{j=1} U_{g_{i}}^{j} \otimes\left[\sum_{i=1}^{n} \sum_{j=1}^{m} U_{g_{i}}^{j}\right]^{-1}$.

'Fuzzy addition' is carried out on $m$ extent analysis values of a fuzzy square matrix as follows:

$\sum_{j=1}^{m} U_{g_{i}}^{j}=\left(\sum_{j=1}^{m} x_{j}, \sum_{j=1}^{m} y_{j}, \sum_{j}^{m} z_{j}\right)$

where $(x, y, z)$ is an FTN.

For calculating $\left[\sum_{i=1}^{n} \sum_{j=1}^{m} U_{g_{i}}^{j}\right]^{-1}$ fuzzy addition of $U_{g_{i}}^{j}$ values is done as follows:

$\sum_{i=1}^{n} \sum_{j=1}^{m} U_{g_{i}}^{j}=\left(\sum_{i=1}^{n} x_{i}, \sum_{i=1}^{n} y_{i}, \sum_{j}^{n} z_{i}\right)$

The inverse of the above is computed:

$\left[\sum_{i=1}^{n} \sum_{j=1}^{m} U_{g_{i}}^{j}\right]^{-1}=\left(\frac{1}{\sum_{i=1}^{n} z_{i}}, \frac{1}{\sum_{i=1}^{n} y_{i}}, \frac{1}{\sum_{i=1}^{n} x_{i}}\right)$.

Step 3 The degree of possibility of the FTNs $U_{1}$ and $U_{2}$ is calculated by using the following:

$V\left(U_{2}>U_{1}\right)=\sup _{w_{2}>w_{1}}\left[\min \left(\mu_{U_{1}}(w), \mu_{U_{2}}(w)\right)\right]$.

where $U_{1} \geq U_{2}$, i.e., $\left(x_{2}, y_{2}, z_{2}\right) \geq\left(x_{1}, y_{1}, z_{1}\right)$.

The values on the axis of the membership function of each enabler are $\mu_{U_{1}}(w)$ and $\mu_{U_{2}}(w)$.

The condition of $V\left(U_{2} \geq U_{1}\right)=1$ is $y_{2} \geq y_{1}$. If $y_{2} \leq y_{1}$, and $V\left(U_{2} \geq U_{1}\right)=\operatorname{hgt}\left(U_{2} \cap U_{1}\right)$. Then:

$V\left(U_{2}>U_{1}\right)=\mu_{d}=\left\{\begin{array}{l}1 \text { if } y_{2}>y_{1} \\ 0 \quad \text { if } x_{2}>z_{2} \\ \frac{x_{1}-z_{2}}{\left(y_{2}-z_{2}\right)-\left(y_{1}-x_{1}\right)} \text { otherwise }\end{array}\right.$.

Figure 1 demonstrates the intersection of two FTNs. The ordinate of highest between $\mu U_{1}$ and $\mu U_{2}$ is ' $T$ '.

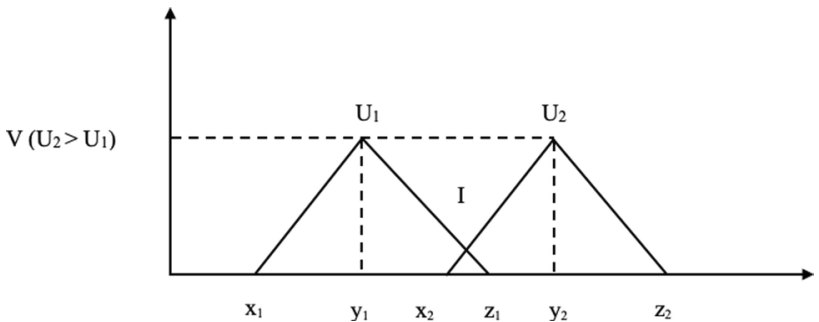

Fig. 1 The interaction between $U_{1}$ and $U_{2}$ (Chang, 1996)

The degree of possibility for an FTN, greater than $k$ TFNs, $U_{i}(i=1,2, \ldots k)$ is given as:

$$
\begin{aligned}
V(U & \left.\geq U_{1}, U_{2}, U_{3} \ldots U_{k}\right) \\
\quad & =V\left[\left(U \geq U_{1}\right) \text { and }\left(U \geq U_{2}\right) \text { and }\left(U \geq U_{k}\right)\right] \\
& =\min V\left(U \geq U_{i}\right), i=1,2,3 \ldots k .
\end{aligned}
$$

Let $s^{\prime}\left(U_{i}\right)=\min V\left(P_{i} \geq P_{k}\right)$ for $k=1,2,3 \ldots n ; k \neq i$. The weights are given as:

$W^{\prime}=\left(s^{\prime}\left(W_{1}\right), s^{\prime}\left(W_{2}\right), \ldots \ldots . . s^{\prime}\left(W_{n}\right)\right)^{T}$,

where $W_{i}(i=1,2,3,4 \ldots n)$ are $n$ factors whose minimum degree of possibility of a fuzzy number being larger than others is taken into consideration.

Step 4 The weight of each enabler ' $W$ ' is calculated by normalization of the above weight vector:

$W=\left(s\left(W_{1}\right), s\left(W_{2}\right), \ldots s\left(W_{n}\right)\right)^{T}$.

After calculation of the weight vector, checking the consistency ratio of the matrix obtained by pairwise assessment is important. Hence, for both the 'mean values matrix' and the 'geometric means matrix', the computation of consistency ratios is carried out (Gogus \& Boucher, 1998). According to Saaty (2008), a consistency ratio $\leq 0.1$ indicates that the matrices are consistent.

\section{Case Description}

The company undergoing the transformation to make its supply chain more responsive is a leading food retail chain having its operations spread across India. The company $X Y Z$ (the name is not revealed for maintaining confidentiality) is "one-stop-shop for fresh shopping, fresh savings and fresh happiness produces." XYZ company, found in 2006, has more than 700 stores across more than 90 cities in India selling fresh fruits and vegetables to dairy, cereals to spices, processed food and beverages to home. The company prides itself on an ecosystem that supports small producers to large producers and has been instrumental in modernizing food 
retail, thereby increasing efficiency in operations and minimizing leakages. Due to increasing global competitiveness and building chorus on the responsiveness of enabled by technologies and their associated benefits thereof, the present company is undergoing the transition from traditional to the responsive supply chain. This coincides with the need for the food supply chains to be responsive in the wake of a pandemic caused by a novel coronavirus (Xu et al., 2020) and augmentation of food supply chains with technologies to increase their responsiveness (Rizou et al., 2020).

The case company is interested in understanding the technology enablers of supply chain responsiveness. The company can focus on the most important factors/enablers and make efforts for their effective implementation. The company also seeks to segregate these enablers by their relative importance to maximize the benefit reaped from them. Data for the investigation of the case company was obtained from the experts' panel. Several rounds of interviews were undertaken to collect the required qualitative and quantitative inputs.

\section{Application of the Proposed Methodology to the Case}

A review of the extant literature was helpful for enlisting a number of enablers of supply chain responsiveness that capitalize upon the technical capability of the firms. A fuzzy Delphi approach was applied to incorporate the expert opinions towards the aptness of enablers enlisted from the literature. A decision team of six experts from industrial and academic backgrounds was formed, and a session was conducted. The panel consists of two senior engineering managers from the case company, two senior managers from the firms that were engaged in implementing new technology platforms to enhance the supply chain responsiveness of the case company, and two researchers primarily doing research in such domain. The panel experts had a cumulative work experience of more than 35 years and are highly skilled. The enlisted enablers were assessed for their suitability by the experts. Their inputs were taken with the help of a linguistic scale shown in Table 2. To this end, a questionnaire was developed. A joint meeting was held online to explain the present study to the experts. The questionnaire was sent to the panel experts. Using the fuzzy Delphi approach, eleven out of fourteen enablers were selected. Table 4 highlights the outcome of the application of fuzzy Delphi. As shown in Table 4, a value $r>0.60$ was considered as a threshold value to decide whether a particular enabler will be considered for fuzzy AHP analysis or not (Kumar et al., 2018). The experts were also requested to suggest any other critical enabler which was missed in the survey of the literature. However, another enabler was not added to the existing list by experts. Hence, after applying the fuzzy Delphi approach, eleven enablers were undertaken for assessment. The selected enablers were taken as an input for fuzzy AHP analysis. For the pairwise comparison of the factors (enablers and dimensions), a second online meeting was held with the panel. Table 4 presents the results of the fuzzy Delphi method. The hierarchy model of selected enablers is depicted in Fig. 2.

The pairwise comparison of each enabler as well as the dimensions was made with the help of an expert panel. The panel of experts remained the same for the fuzzy Delphi and fuzzy AHP approach, in cognizance with the existing studies. Every expert was asked to provide a rating to each enabler on the basis of its relative importance in the pairwise comparison with other enablers. For doing this exercise, the linguistic scale defined in Table 3 was utilized by
Table 4 Results of fuzzy Delphi method

\begin{tabular}{llllll}
\hline Enabler & $M_{l}$ & $N_{l}$ & $O_{l}$ & $S_{l}$ & Selected/rejected \\
\hline Supply chain integration technologies & 0.43 & 0.56 & 0.82 & 0.6 & Selected \\
Predictive analytics for resource optimization & 0.48 & 0.65 & 0.95 & 0.7 & Selected \\
Smart logistics technologies & 0.48 & 0.65 & 0.95 & 0.7 & Selected \\
Smart warehousing & 0.48 & 0.65 & 0.95 & 0.7 & Selected \\
RFID-based location tracking & 0.45 & 0.59 & 0.86 & 0.63 & Selected \\
Drone logistics & 0.25 & 0.32 & 0.45 & 0.34 & Not selected \\
Online transparent presence & 0.43 & 0.56 & 0.82 & 0.6 & Selected \\
Sustainable manufacturing technologies & 0.43 & 0.56 & 0.82 & 0.6 & Selected \\
Smart retail technology & 0.48 & 0.65 & 0.95 & 0.7 & Selected \\
Big data and cloud-based demand prediction & 0.46 & 0.66 & 0.98 & 0.76 & Selected \\
AI for supply network and monitoring & 0.58 & 0.81 & 0.88 & 0.71 & Selected \\
Sustainable food packaging & 0.48 & 0.65 & 0.95 & 0.7 & Selected \\
Blockchain for traceability & 0.48 & 0.65 & 0.95 & 0.7 & Selected \\
Smart order management technologies & 0.36 & 0.48 & 0.7 & 0.51 & Not Selected \\
Sustainable sourcing and distribution & 0.45 & 0.59 & 0.86 & 0.63 & Selected \\
\hline
\end{tabular}




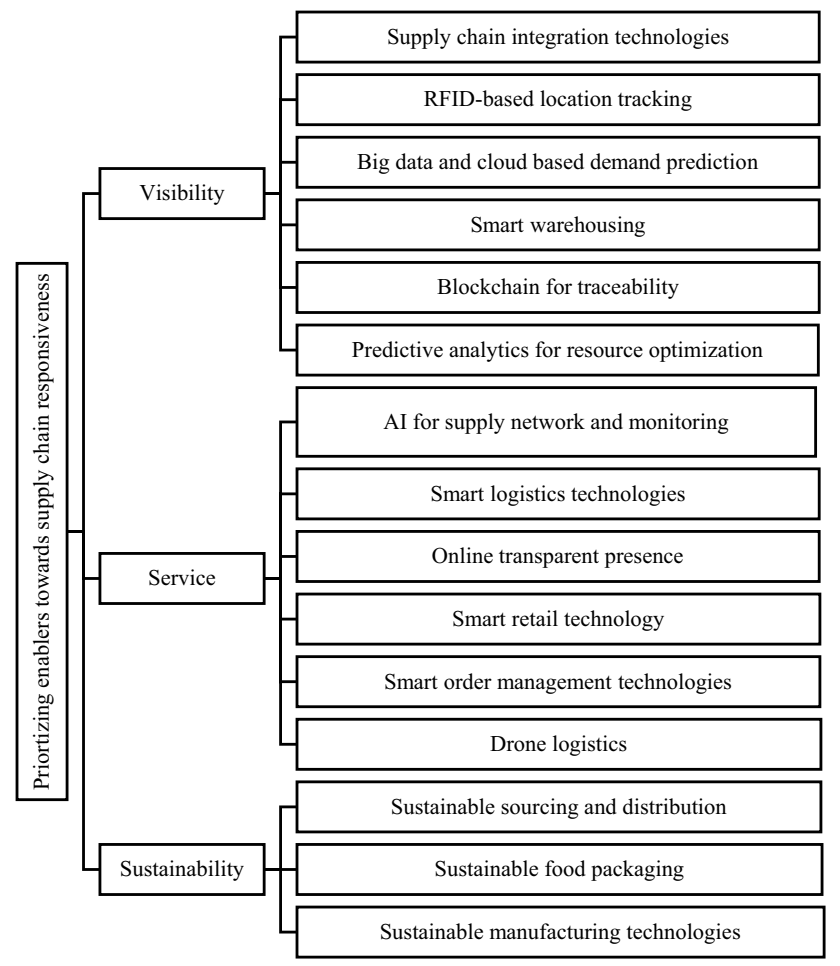

Fig. 2 A hierarchy model of selected enablers

the panel members. Once the rating has been obtained, the corresponding fuzzy number replaced the linguistic scale value (see Table 3 ). The weights of enablers were computed with the help of the extent analysis method, as explained earlier. Table 5 presents the pairwise comparison matrix for enabler dimensions.

The consistency ratio method was utilized to check the consistency of the matrices. The weights of enabler dimensions are given in Table 6 . The pairwise comparisons of enablers are carried out in Tables 7, 8, and 9. The composite weight of each enabler is calculated by multiplying the dimension weight to enabler weight, and the corresponding global ranks are obtained (see Table 10).

\section{Discussion}

In this section, we illustrate the research findings of this study to assist the case study in implementing various technologies and tools to enhance the responsiveness of their supply chain.

The supply chain integration technologies (V6) enabler obtains the first rank among the enablers. Firms nowadays derive their competitiveness from their supply chains. A well-integrated supply chain enhances the probability of a firm achieving above-normal profits. Supply chain integration technologies can help to integrate the entire supply chain, both upstream and downstream, to increase visibility and transparency, which become of paramount importance in the wake of external shocks (Kumar et al., 2020). These technologies include electronic data exchange, internet, automatic identification, and data capture, open standards, decision-making information systems, and World Wide Web (WWW), which enhances collaboration in supply chain partners (Shamim et al., 2017). Therefore, augmenting supply chain integration technologies to increase the responsiveness of supply chains is of critical value and enhances the competitive advantage and performance of a firm (Singh, 2015).

Sustainable manufacturing technologies $\left(S^{\prime} 1\right)$ together rank second in the analysis as they drive supply chain responsiveness. The findings resonate with the study conducted by Moktadir et al., (2021) in the leather industry of Bangladesh. The results revealed that sustainable manufacturing practices have the capabilities of reducing waste generation and promote effective utilization of the
Table 5 Pairwise comparison matrix for enabler dimensions

\begin{tabular}{llllllllll}
\hline & $V$ & \multicolumn{9}{c}{$O$} & \multicolumn{7}{c}{$S$} \\
\hline$V$ & 1.00 & 1.00 & 1.00 & 1.06 & 1.55 & 2.17 & 0.92 & 1.43 & 2.05 \\
$O$ & 0.46 & 0.64 & 0.94 & 1.00 & 1.00 & 1.00 & 0.74 & 1.08 & 1.64 \\
$S$ & 0.49 & 0.70 & 1.08 & 0.61 & 0.92 & 1.35 & 1.00 & 1.00 & 1.00 \\
\hline $\mathrm{CR}_{\mathrm{m}}=0.003, \mathrm{CR}_{\mathrm{g}}=0.01$ & & & & & &
\end{tabular}

Table 6 Relative weights using fuzzy synthetic extent method

\begin{tabular}{lllllllllll}
\hline Fuzzy sum of each row & \multicolumn{2}{l}{ Fuzzy synthetic extent } & Degree of possibility & Weights $\begin{array}{l}\text { Normal- } \\
\text { ized } \\
\text { weights }\end{array}$ \\
\hline 2.98 & 3.98 & 5.22 & 0.24 & 0.43 & 0.72 & & 1.00 & 1.00 & 1.00 & 0.44 \\
2.20 & 2.73 & 3.59 & 0.18 & 0.29 & 0.49 & 0.65 & & 1.00 & 0.65 & 0.29 \\
2.10 & 2.62 & 3.44 & 0.17 & 0.28 & 0.47 & 0.61 & 0.96 & & 0.61 & 0.27 \\
\hline
\end{tabular}


Table 7 Pairwise comparison of visibility dimension enablers

\begin{tabular}{|c|c|c|c|c|c|c|c|c|c|c|c|c|c|c|c|c|c|c|c|}
\hline & $V 1$ & & & $V 2$ & & & $V 3$ & & & $V 4$ & & & $V 5$ & & & V6 & & & $\begin{array}{l}\text { Normal- } \\
\text { ized } \\
\text { weights }\end{array}$ \\
\hline$V 1$ & 1.00 & 1.00 & 1.00 & 1.06 & 1.55 & 2.17 & 0.31 & 0.38 & 0.53 & 0.64 & 0.87 & 1.25 & 1.15 & 1.64 & 2.05 & 1.06 & 1.55 & 2.17 & 0.18 \\
\hline$V 2$ & 0.46 & 0.64 & 0.94 & 1.00 & 1.00 & 1.00 & 1.32 & 2.05 & 2.70 & 0.92 & 1.43 & 2.05 & 1.06 & 1.55 & 2.17 & 1.52 & 2.22 & 2.86 & 0.24 \\
\hline$V 3$ & 1.89 & 2.61 & 3.25 & 0.37 & 0.49 & 0.76 & 1.00 & 1.00 & 1.00 & 1.32 & 2.05 & 2.70 & 1.32 & 2.05 & 2.70 & 1.32 & 2.05 & 2.70 & 0.27 \\
\hline$V 4$ & 0.80 & 1.15 & 1.55 & 0.49 & 0.70 & 1.08 & 0.37 & 0.49 & 0.76 & 1.00 & 1.00 & 1.00 & 0.84 & 1.23 & 1.73 & 1.00 & 1.74 & 2.41 & 0.16 \\
\hline$V 5$ & 0.49 & 0.61 & 0.87 & 0.46 & 0.64 & 0.94 & 0.37 & 0.49 & 0.76 & 0.64 & 0.87 & 1.25 & 1.00 & 1.00 & 1.00 & 1.00 & 1.32 & 1.55 & 0.10 \\
\hline V6 & 0.46 & 0.64 & 0.94 & 0.35 & 0.45 & 0.66 & 0.37 & 0.49 & 0.76 & 0.42 & 0.57 & 1.00 & 0.64 & 0.76 & 1.00 & 1.00 & 1.00 & 1.00 & 0.06 \\
\hline
\end{tabular}

$\mathrm{CR}_{\mathrm{m}}=0.05, \mathrm{CR}_{\mathrm{g}}=0.10$

Table 8 Pairwise comparison of service dimension enablers

\begin{tabular}{|c|c|c|c|c|c|c|c|c|c|c|c|c|c|}
\hline & $A$ & & & $B$ & & & $C$ & & & $D$ & & & $\begin{array}{l}\text { Normal- } \\
\text { ized } \\
\text { weights }\end{array}$ \\
\hline$A$ & 1.00 & 1.00 & 1.00 & 1.32 & 2.05 & 2.70 & 0.61 & 0.92 & 1.35 & 0.80 & 1.15 & 1.55 & 0.31 \\
\hline$B$ & 0.37 & 0.49 & 0.76 & 1.00 & 1.00 & 1.00 & 0.61 & 0.92 & 1.35 & 0.61 & 0.92 & 1.35 & 0.19 \\
\hline$C$ & 0.74 & 1.08 & 1.64 & 0.74 & 1.08 & 1.64 & 1.00 & 1.00 & 1.00 & 0.80 & 1.15 & 1.55 & 0.26 \\
\hline$D$ & 0.64 & 0.87 & 1.25 & 0.74 & 1.08 & 1.64 & 0.64 & 0.87 & 1.25 & 1.00 & 1.00 & 1.00 & 0.23 \\
\hline
\end{tabular}

\begin{tabular}{lllllllllll}
\hline & S1 & & & S2 & & & S3 & & & $\begin{array}{l}\text { Normal- } \\
\text { ized } \\
\text { weights }\end{array}$ \\
\hline$S 1$ & 1.00 & 1.00 & 1.00 & 1.52 & 2.22 & 2.86 & 0.92 & 1.43 & 2.05 & 0.58 \\
$S 2$ & 0.35 & 0.45 & 0.66 & 1.00 & 1.00 & 1.00 & 1.00 & 1.32 & 1.55 & 0.23 \\
$S 3$ & 0.49 & 0.70 & 1.08 & 0.58 & 0.71 & 1.00 & 1.00 & 1.00 & 1.00 & 0.19 \\
\hline
\end{tabular}

$\mathrm{CR}_{\mathrm{m}}=0.04, \mathrm{CR}_{\mathrm{g}}=0.8$

resources. These practices will also provide them a competitive advantage and will help in the long-term survival of the firms (Katiyar et al., 2018). Apart from providing a competitive advantage, sustainable manufacturing processes can enhance the control of the firm towards different supply chain processes (Kumar \& Kumar Singh, 2021). Therefore, sustainable practices are considered a crucial driver of supply chain responsiveness.

The smart warehousing $(V 2)$ enabler ranks third amongst the list of enablers in the technology enablers of supply chain responsiveness in the food sector. The very distinction between the traditional and smart warehouse is that of efficiency with which the smart warehouse operates, unlike their counterparts which are inefficient due to manual handling of tasks (Kumar et al., 2021a, 2021b). Smart warehouse pride on minimal manual handling and integration of best practices resulting in maximum efficiency (Jabbar et al., 2018). Tasks such as those of pickup, bookkeeping, and delivery should be automated in a warehouse (Liu et al., 2018). A key framework for a smart warehouse is cyber-physical systems consisting of mainly four building blocks- robots, humans, CPS devices, and inventories. Implementing a smart warehouse creates immense efficiencies with such time-efficient communication and human activities recognition (Liu et al., 2018).

The RFID-based location tracking (V3) is ranked fourth in the analysis. The RFID is a class of technologies that have shown great promise in bridging the vast information gaps that exist within and beyond the firm and therefore obtains the fourth rank (Angeles, 2007). RFID technologies are touted to be a class of technologies that introduce "process freedoms" with which value can be added along the entire supply chain requiring an effective redesigning of business processes (Zhu et al., 2012). RFID technologies have been instrumental in changing how logistics are managed in supply chains. Traditional technologies such as enterprise resource planning or customer relationship management do increase 
Table 10 Final ranking of enablers

\begin{tabular}{|c|c|c|c|c|c|c|c|}
\hline Dimension & Relative weight & Enabler & Enabler & Relative weights & Relative rank & Global weights & Global rank \\
\hline \multirow[t]{6}{*}{ Visibility } & \multirow[t]{6}{*}{0.44} & $V 1$ & Blockchain for traceability & 0.209 & 5 & 0.092 & 6 \\
\hline & & $V 2$ & Smart warehousing & 0.253 & 2 & 0.111 & 3 \\
\hline & & $V 3$ & RFID-based location tracking & 0.22 & 3 & 0.097 & 4 \\
\hline & & $V 4$ & $\begin{array}{l}\text { Big data and cloud-based demand } \\
\text { prediction }\end{array}$ & 0.218 & 4 & 0.096 & 5 \\
\hline & & $V 5$ & $\begin{array}{l}\text { Predictive analytics for resource } \\
\text { optimization }\end{array}$ & 0.099 & 6 & 0.044 & 13 \\
\hline & & $V 6$ & $\begin{array}{l}\text { Supply chain integration technolo- } \\
\text { gies }\end{array}$ & 0.537 & 1 & 0.236 & 1 \\
\hline \multirow[t]{4}{*}{ Service } & \multirow[t]{4}{*}{0.29} & $S 1$ & Smart logistics technologies & 0.308 & 1 & 0.089 & 7 \\
\hline & & $S 2$ & Smart retail technology & 0.195 & 4 & 0.056 & 11 \\
\hline & & $S 3$ & $\begin{array}{l}\text { AI for supply network and monitor- } \\
\text { ing }\end{array}$ & 0.265 & 2 & 0.077 & 8 \\
\hline & & $S 4$ & Online transparent presence & 0.232 & 3 & 0.067 & 9 \\
\hline \multirow[t]{3}{*}{ Sustainability } & \multirow[t]{3}{*}{0.27} & $S^{\prime} 1$ & $\begin{array}{l}\text { Sustainable manufacturing technolo- } \\
\text { gies }\end{array}$ & 0.579 & 1 & 0.156 & 2 \\
\hline & & $S^{\prime} 2$ & $\begin{array}{l}\text { Sustainable sourcing and distribu- } \\
\text { tion }\end{array}$ & 0.231 & 2 & 0.062 & 10 \\
\hline & & $S^{\prime} 3$ & Sustainable food packaging & 0.190 & 3 & 0.051 & 12 \\
\hline
\end{tabular}

the supply chain efficiency, albeit in a limited manner (Singh et al., 2019). This deficiency is mitigated by the use of RFID technologies as the benefits of efficiency and timeliness accrue in the entire supply chain, thereby increasing supply chain visibility, doing away with the human-induced latency. All this increases the supply chain responsiveness (Giannakis et al., 2019).

The results of this research confer the fifth rank to Big data and cloud computing technologies (V4) towards increasing the supply chain responsiveness. These technologies have caught the attention of all industries and countries due to the value-additions voluminous data can have on the conduct of the business (Addo-Tenkorang \& Helo, 2016). These technologies help firms to do real-time analysis of data augmented by analytics that can be hosted on the cloud and consumer by consumers (Assunção et al., 2015). The findings of the study are in line with the extant literature. For example, authors have argued that the solutions from big data also increase the real-time end-to-end visibility in the supply chain, thereby enhancing its responsiveness (Kumar et al., 2021a, 2021b). Further, the analytics provided by big data drive time compression, which is the essential characteristic of a responsive supply chain to react efficiently in the wake of external environmental shocks (Kache \& Seuring, 2017). Therefore, it is essential to the value of big data technologies and analytics in enhancing the supply chain chains and thereby unlocking their true potential.

Predictive analytics for resource optimization (V5) of products rank second, last, and last in our analysis. Since the results of the analysis are based on the judgment of the expert panel, certain reasons can lead to this counterintuitive finding. Scholars point towards a much lesser adoption of predictive analytics in the context of Indian food supply chains, as compared to descriptive and prescriptive analytics, the reason being high cost and resistance to change (Kamble et al., 2020). The opinion of experts in the present study can be attributed to similar reasoning, as a result of which predictive analytics is deemed unimportant.

As evident from the analysis, several factors (enablers) play a crucial role in enhancing a firm's proactiveness towards becoming more responsive in the wake of the pandemic. This is in accordance with contingency theory, which suggests that the internal and external situation of a firm decides the optimum course of action (Grötsch et al., 2013). COVID19 is the contingency being faced by the supply chains, and the level of disruptions faced by the firms are major indicators of the contingent situation (Grötsch et al., 2013). In line with the contingency approach, for managing these disruptions, the supply chains need to improve and enhance their technological capability proactively.

\section{Conclusions}

The present study provides a structured view of technology-driven enablers from the perspective of the food supply chains that intend to enhance their responsiveness. The ongoing COVID-19 crisis acts as the important contingent factor faced by the organizations and therefore the contingency theory acts as a theoretical lens for the analysis. 
Critical enablers of responsiveness, driven by digitalization have been identified with the help of a literature survey and the opinion of experts. The enablers are assessed from the standpoint of a firm that is transitioning towards responsive supply chains. The fuzzy Delphi technique is used to finalize the important enablers. Further, fuzzy AHP establishes their relative importance. The analysis reveals that supply chain integration technologies, sustainable manufacturing technologies, and smart warehousing are the top three enablers of supply chain responsiveness in the food sector. Further, the study provides academic and managerial implications which are discussed below.

\section{Academic Implications}

This research work presents a systematic approach to rank, prioritize and choose from a set of technologies to enhance the supply chain responsiveness by taking an example from the food sector, which is an under-researched area in the extant literature. This need is escalated in developing economies to arrest the difficulties caused by inefficiencies in the food supply chain and further intensified by pressures of COVID19. This work identifies key technology enablers through an extensive literature review and through fuzzy Delphi method reduced the number of these enablers, which were then subject to fuzzy AHP process to rank and prioritize these enablers. Finally, we discuss the top four ranked technology enablers - supply chain integration technology, RFID, smart warehousing, and big data and cloud computing as. This work is of particular significance for managers and practitioners to focus on the top-ranked enablers to achieve the much-needed responsiveness in the food supply chain.

\section{Managerial Implications}

From the managerial point of view, the research highlights that choosing from a myriad of technology solutions is challenging and sometimes overwhelming. Previous research, which pursues the idea of supply chain responsiveness, identifies different ways and tools to enhance it, yet the literature presents ambiguities with reference to different technologies. This work highlights the various technology-led enablers that can improve the supply chain responsiveness of the food supply chain. A clear and proper understanding of these technology enablers is critical for achieving competitiveness in the supply chain. The study outlines the key enablers that will highlight the strategic field of action for the managers to improve supply chain responsiveness. Responsiveness strategy is an important approach to revive operations and supply chains in post-COVID-19 times. Moreover, business leaders should pay attention to the most important enablers to fare better in the competition globally. This research clearly demonstrates that to achieve responsiveness in the supply chain, managers need to implement supply chain integration technologies, both upstream and downstream, apart from using RFID, smart warehousing, and big data and cloud computing technologies. The process of achieving the supply chain responsiveness is complex, accentuated by the current global pandemic, and hence, with this research, we disentangle the technological opportunities to achieve the same. With supply chain integration and smart warehousing getting enumerated in the top four technologies requires firms to adopt a twopronged strategy - train and educate the members of your supply chain to achieve supply chain responsiveness through technologies' driven enablers and their intended benefits, and initiate training for employees to change the internal dynamics of the firm as well.

\section{Limitations and Directions for Future Research}

This research has certain limitations. The methods used include fuzzy Delphi and Fuzzy AHP to determine the weights of the enablers. This process is cumbersome and involves a high level of human engagement, and therefore, requires extreme care. Future researchers can, therefore, use several other methodological tools such as those of largescale survey methodology resulting in an extensive data set and fine-grained qualitative case study analysis, among others, to disentangle this complex process further. The findings of this research should be understood with caution as these are country-specific as well. This should pave the way for further research in different countries. This can further aid in our understanding of the supply chain responsiveness through country-specific contextualization and comparisons and underlying idiosyncrasies. The experts' data and findings of the present study are principally based on the food industry. This may limit the generalizability of the results with respect to other industries of varying types, sizes, etc. Therefore, there is scope for further research on the identification of enablers in other supply chains such as healthcare, wellness, etc., which can be assessed. Therefore, empirical examinations can also be carried out, and diverse sample sets could be assessed to identify and evaluate enablers related to responsive supply chains, and the finding may be compared with the present study findings.

Finally, the realized benefits of supply chain responsiveness should be assessed in future research to validate the use of specific technologies and tools.

\section{Key Questions Reflecting Real-Life Applicability}

1. What role does the food sector play in the growth of the digital economy? How is the developing country scenario different from that of the developed? 
2. Which smart technologies and digitalization principles lead to a trade-off between minimized human contact as well as enhanced responsiveness?

3. In post-COVID-19 pandemic times, which supply chains underwent maximum breakthrough to enhance responsiveness?

4. How do technology-driven enablers differ in developing and developed countries in terms of adoption patterns, and why?

Acknowledgements We express our gratitude towards all the anonymous reviewers, the special issue editors, editors at JGBC and the Editor-in-Chief, for their valuable comments and suggestions that led to a considerable improvement of this study. We are also thankful to all experts for sharing their valued inputs through structured and informal interactions, which helped us with the analysis. The infrastructural support provided by FORE School of Management, New Delhi in completing this paper gratefully acknowledged.

Author contributions CC: ideas, conceptualisation, writing-original draft preparation, methodology, data collection, formal analysis, revision. MUA: ideas, conceptualisation, writing-original draft preparation, project administration, commentary and revision. DG: critical review, investigation, writing-original draft preparation formatting and editing, commentary and revision.

Funding No funding was received for the research work.

Availability of data and material Data available on request.

Code availability NA.

\section{Declarations}

Conflict of interest On behalf of all authors, the corresponding author states that there is no conflict of interest.

\section{References}

Acar, M. F., Aktas, E., Agan, Y., \& Bourlakis, M. (2019). Does sustainability pay? Evidence from the food sector. Journal of Foodservice Business Research, 22(3), 239-260. https://doi.org/10.1080/15378 020.2019 .1597672

Addo-Tenkorang, R., \& Helo, P. T. (2016). Big data applications in operations/supply-chain management: A literature review. Computers and Industrial Engineering. https://doi.org/10.1016/j.cie. 2016.09.023

Aftab, M. A., Yuanjian, Q., Kabir, N., \& Barua, Z. (2018). Super responsive supply chain: The case of Spanish Fast Fashion Retailer Inditex-Zara. International Journal of Business and Management, 13(5), 212. https://doi.org/10.5539/ijbm.v13n5p212

Angeles, R. (2007). RFID technologies: Supply-chain applications and implementation issues. IEEE Engineering Management Review. https://doi.org/10.1109/emr.2007.382639

Assunção, M. D., Calheiros, R. N., Bianchi, S., Netto, M. A. S., \& Buyya, R. (2015). Big Data computing and clouds: Trends and future directions. Journal of Parallel and Distributed Computing. https://doi.org/10.1016/j.jpdc.2014.08.003

Astill, J., Dara, R. A., Campbell, M., Farber, J. M., Fraser, E. D. G., Sharif, S., \& Yada, R. Y. (2019). Transparency in food supply chains: A review of enabling technology solutions. Trends in Food Science and Technology. https://doi.org/10.1016/j.tifs.2019.07.024

Aung, M. M., \& Chang, Y. S. (2014). Traceability in a food supply chain: Safety and quality perspectives. Food Control. https://doi. org/10.1016/j.foodcont.2013.11.007

Bouzon, M., Govindan, K., Rodriguez, C. M. T., \& Campos, L. M. S. (2016). Identification and analysis of reverse logistics barriers using fuzzy Delphi method and AHP. Resources, Conservation and Recycling, 108, 182-197. https://doi.org/10.1016/j.resconrec. 2015.05.021

Buckley, J. J. (1985). Fuzzy hierarchical analysis. Fuzzy Sets and Systems, 17(3), 233-247. https://doi.org/10.1016/0165-0114(85) 90090-9

Chang, D.-Y. (1996). Applications of the extent analysis method on fuzzy AHP. European Journal of Operational Research, 95(3), 649-655. https://doi.org/10.1016/0377-2217(95)00300-2

Chauhan, C., \& Singh, A. (2020). Analysis of challenges responsible for the slow pace of industry 4.0 diffusion. International Journal of Strategic Decision Sciences. https://doi.org/10.4018/ijsds.20200 40104

Deconinck, K., Avery, E., \& Jackson, L. A. (2020). Food supply chains and covid-19: Impacts and policy lessons. EuroChoices. https:// doi.org/10.1111/1746-692X.12297

Deshmukh, S. G., \& Haleem, A. (2020). Framework for manufacturing in post-COVID-19 world order: An Indian perspective. International Journal of Global Business and Competitiveness, 15(1), 49-60. https://doi.org/10.1007/s42943-020-00009-1

Di Vaio, A., Boccia, F., Landriani, L., \& Palladino, R. (2020). Artificial intelligence in the agri-food system: Rethinking sustainable business models in the COVID-19 scenario. Sustainability (switzerland). https://doi.org/10.3390/SU12124851

Dubey, R., Gunasekaran, A., Papadopoulos, T., \& Childe, S. J. (2015). Green supply chain management enablers: Mixed methods research. Sustainable Production and Consumption, 4, 72-88. https://doi.org/10.1016/j.spc.2015.07.001

Frederico, G. F. (2021). Towards a Supply Chain 40 on the postCOVID-19 pandemic: a conceptual and strategic discussion for more resilient supply chains. Rajagiri Management Journal. https://doi.org/10.1108/RAMJ-08-2020-0047 (ahead-of-print).

Giannakis, M., Spanaki, K., \& Dubey, R. (2019). A cloud-based supply chain management system: Effects on supply chain responsiveness. Journal of Enterprise Information Management. https://doi.org/10. 1108/JEIM-05-2018-0106

Godsell, J., Harrison, A., Emberson, C., \& Storey, J. (2006). Customer responsive supply chain strategy: An unnatural act? International Journal of Logistics Research and Applications. https://doi.org/10. 1080/13675560500534664

Gogus, O., \& Boucher, T. O. (1998). Fuzzy NCIC. Engineering Economist, 43(3), 203-246. https://doi.org/10.1080/00137919808903197

Grötsch, V. M., Blome, C., \& Schleper, M. C. (2013). Antecedents of proactive supply chain risk management-a contingency theory perspective. International Journal of Production Research, 51(10), 2842-2867. https://doi.org/10.1080/00207543.2012.746796

Gunasekaran, A., Lai, K., \& Cheng, T. C. E. (2008). Responsive supply chain: A competitive strategy in a networked economy. Omega. https://doi.org/10.1016/j.omega.2006.12.002

Gupta, A., Singh, R. K., \& Mangla, S. K. (2021). Evaluation of logistics providers for sustainable service quality: Analytics based decision making framework. Annals of Operations Research. https://doi.org/ 10.1007/s10479-020-03913-0

Irani, Z., Sharif, A. M., Lee, H., Aktas, E., Topaloğlu, Z., van't Wout, T., \& Huda, S. (2018). Managing food security through food 
waste and loss: Small data to big data. Computers and Operations Research, 98, 367-383. https://doi.org/10.1016/j.cor.2017.10.007

Ishikawa, A., Amagasa, M., Shiga, T., Tomizawa, G., Tatsuta, R., \& Mieno, H. (1993). The max-min Delphi method and fuzzy Delphi method via fuzzy integration. Fuzzy Sets and Systems, 55(3), 241-253. https://doi.org/10.1016/0165-0114(93)90251-C

Ishtiaque, S., Siddiqui, D. A., \& Ahmed, W. (2020). Impact of technology-based integrated responsive supply chain on operational performance: A case of a volatile market. International Journal of Logistics Systems and Management. https://doi.org/10.1504/ IJLSM.2020.105917

Jabbar, S., Khan, M., Silva, B. N., \& Han, K. (2018). A RESTbased industrial web of things' framework for smart warehousing. Journal of Supercomputing. https://doi.org/10.1007/ s11227-016-1937-y

Kache, F., \& Seuring, S. (2017). Challenges and opportunities of digital information at the intersection of big data analytics and supply chain management. Journal of Management Development, 37(1), 10-36. https://doi.org/10.1108/MBE-09-2016-0047

Kamble, S. S., Gunasekaran, A., \& Gawankar, S. A. (2020). Achieving sustainable performance in a data-driven agriculture supply chain: A review for research and applications. International Journal of Production Economics. https://doi.org/10.1016/j.ijpe. 2019.05.022

Katiyar, R., Meena, P. L., Barua, M. K., Tibrewala, R., \& Kumar, G. (2018). Impact of sustainability and manufacturing practices on supply chain performance: Findings from an emerging economy. International Journal of Production Economics. https://doi.org/ 10.1016/j.ijpe.2017.12.007

Kim, M., Suresh, N. C., \& Kocabasoglu-Hillmer, C. (2013). An impact of manufacturing flexibility and technological dimensions of manufacturing strategy on improving supply chain responsiveness: Business environment perspective. International Journal of Production Research. https://doi.org/10.1080/00207543.2013.790569

Kumar, A., Zavadskas, E. K., Mangla, S. K., Agrawal, V., Sharma, K., \& Gupta, D. (2018). When risks need attention: Adoption of green supply chain initiatives in the pharmaceutical industry. International Journal of Production Research. https://doi.org/10.1080/ 00207543.2018.1543969

Kumar, N., Kumar, G., \& Singh, R. K. (2021a). Big data analytics application for sustainable manufacturing operations: Analysis of strategic factors. Clean Technologies and Environmental Policy. https://doi.org/10.1007/s10098-020-02008-5

Kumar, P., \& Kumar Singh, R. (2021). Strategic framework for developing resilience in agri-food supply chains during COVID 19 pandemic. International Journal of Logistics Research and Applications. https://doi.org/10.1080/13675567.2021.1908524

Kumar, R., Singh, R. K., \& Dwivedi, Y. K. (2020). Application of industry 4.0 technologies in SMEs for ethical and sustainable operations: Analysis of challenges. Journal of Cleaner Production, 275, 124063. https://doi.org/10.1016/j.jclepro.2020.124063

Kumar, S., Raut, R. D., Narwane, V. S., Narkhede, B. E., \& Muduli, K. (2021b). Implementation barriers of smart technology in Indian sustainable warehouse by using a Delphi-ISM-ANP approach. International Journal of Productivity and Performance Management. https://doi.org/10.1108/IJPPM-10-2020-0511

Li, L. (2012). Effects of enterprise technology on supply chain collaboration: Analysis of China-linked supply chain. Enterprise Information Systems. https://doi.org/10.1080/17517575.2011.639904

Liu, X., Cao, J., Yang, Y., \& Jiang, S. (2018). CPS-based smart warehouse for industry 4.0: A survey of the underlying technologies. Computers. https://doi.org/10.3390/computers7010013

Mahroof, K. (2019). A human-centric perspective exploring the readiness towards smart warehousing: The case of a large retail distribution warehouse. International Journal of Information Management. https://doi.org/10.1016/j.ijinfomgt.2018.11.008
Makkonen, H., Pohjola, M., Olkkonen, R., \& Koponen, A. (2014). Dynamic capabilities and firm performance in a financial crisis. Journal of Business Research, 67(1), 2707-2719. https://doi.org/ 10.1016/j.jbusres.2013.03.020

McAdam, R., Miller, K., \& McSorley, C. (2019). Towards a contingency theory perspective of quality management in enabling strategic alignment. International Journal of Production Economics. https:// doi.org/10.1016/j.ijpe.2016.07.003

Mikkonen, K. S., \& Tenkanen, M. (2012). Sustainable food-packaging materials based on future biorefinery products: Xylans and mannans. Trends in Food Science and Technology. https://doi.org/10. 1016/j.tifs.2012.06.012

Moktadir, M. A., Dwivedi, A., Khan, N. S., Paul, S. K., Khan, S. A., Ahmed, S., \& Sultana, R. (2021). Analysis of risk factors in sustainable supply chain management in an emerging economy of leather industry. Journal of Cleaner Production. https://doi.org/ 10.1016/j.jclepro.2020.124641

Momaya, K. S. (2020). Return from COVID-19: Thinking differently about export competitiveness and sustainability. International Journal of Global Business and Competitiveness, 15(1), 1-9. https://doi.org/10.1007/s42943-020-00012-6

Piprani, A. Z., Jaafar, N. I., \& Mohezar Ali, S. (2020). Prioritizing resilient capability factors of dealing with supply chain disruptions: An analytical hierarchy process (AHP) application in the textile industry. Benchmarking. https://doi.org/10.1108/BIJ-03-2019-0111

Pramatari, K., Karagiannaki, A., \& Bardaki, C. (2010). Radio frequency identification (RFID) as a catalyst for improvements in food supply chain operations. In: Mena, C., \& Stevens, G. (Eds.). Delivering performance in food supply chains (pp. 432-455). Elsevier. https:// doi.org/10.1533/9781845697778.5.432

Rakyta, M., Fusko, M., Herčko, J., Závodská, L., \& Zrnić, N. (2016). Proactive approach to smart maintenance and logistics as a auxiliary and service processes in a company. Journal of Applied Engineering Science, 14(4), 433-442. https://doi.org/10.5937/ jaes14-11664

Randall, T. R., Morgan, R. M., \& Morton, A. R. (2003). Efficient versus responsive supply chain choice: An empirical examination of influential factors. Journal of Product Innovation Management. https://doi.org/10.1111/1540-5885.00041

Riahi, Y., Saikouk, T., Gunasekaran, A., \& Badraoui, I. (2021). Artificial intelligence applications in supply chain: A descriptive bibliometric analysis and future research directions. Expert Systems with Applications. https://doi.org/10.1016/j.eswa.2021.114702

Rizou, M., Galanakis, I. M., Aldawoud, T. M. S., \& Galanakis, C. M. (2020). Safety of foods, food supply chain and environment within the COVID-19 pandemic. Trends in Food Science and Technology. https://doi.org/10.1016/j.tifs.2020.06.008

Roh, J., Hong, P., \& Min, H. (2014). Implementation of a responsive supply chain strategy in global complexity: The case of manufacturing firms. International Journal of Production Economics. https://doi.org/10.1016/j.ijpe.2013.04.013

Saaty, T. L. (2008). Decision making with the analytic hierarchy process. International Journal of Services Sciences, 1(1), 83. https:// doi.org/10.1504/IJSSCI.2008.017590

Sah, B., Gupta, R., \& Bani-Hani, D. (2020). Analysis of barriers to implement drone logistics. International Journal of Logistics Research and Applications. https://doi.org/10.1080/13675567. 2020.1782862

Shamim, S., Cang, S., Yu, H., \& Li, Y. (2017). Examining the feasibilities of industry 4.0 for the hospitality sector with the lens of management practice. Energies, 10(4), 499. https://doi.org/10. 3390/en10040499

Singh, R. K. (2015). Modelling of critical factors for responsiveness in supply chain. Journal of Manufacturing Technology Management. https://doi.org/10.1108/JMTM-04-2014-0042 
Singh, R. K., Luthra, S., Mangla, S. K., \& Uniyal, S. (2019). Applications of information and communication technology for sustainable growth of SMEs in India food industry. Resources, Conservation and Recycling. https://doi.org/10.1016/j.resconrec.2019.04.014

Singh, S., Kumar, R., Panchal, R., \& Tiwari, M. K. (2021). Impact of COVID-19 on logistics systems and disruptions in food supply chain. International Journal of Production Research. https://doi. org/10.1080/00207543.2020.1792000

Sinkovics, R. R., Jean, R. J. B., Roath, A. S., \& Cavusgil, S. T. (2011). Does IT integration really enhance supplier responsiveness in global supply chains? Management International Review. https:// doi.org/10.1007/s11575-011-0069-0

Stranieri, S., Riccardi, F., Meuwissen, M. P. M., \& Soregaroli, C. (2021). Exploring the impact of blockchain on the performance of agri-food supply chains. Food Control, 119, 107495. https://doi. org/10.1016/j.foodcont.2020.107495

Van Der Vorst, J. G. A. J., Tromp, S. O., \& Van Der Zee, D. J. (2009). Simulation modelling for food supply chain redesign; integrated decision making on product quality, sustainability and logistics. International Journal of Production Research. https://doi.org/10. 1080/00207540802356747

Williams, B. D., Roh, J., Tokar, T., \& Swink, M. (2013). Leveraging supply chain visibility for responsiveness: The moderating role of internal integration. Journal of Operations Management. https:// doi.org/10.1016/j.jom.2013.09.003

Wuenderlich, N. V., Heinonen, K., Ostrom, A. L., Patricio, L., Sousa, R., Voss, C., \& Lemmink, J. G. A. M. (2015). "Futurizing" smart service: Implications for service researchers and managers. Journal of Services Marketing. https://doi.org/10.1108/JSM-01-2015-0040

$\mathrm{Xu}, \mathrm{Z}$., Elomri, A., Kerbache, L., \& El Omri, A. (2020). Impacts of COVID-19 on global supply chains: Facts and perspectives. IEEE Engineering Management Review, 48(3), 153-166. https://doi.org/ 10.1109/EMR.2020.3018420

Yadav, N., Shankar, R., \& Singh, S. P. (2021). Hierarchy of critical success factors (CSF) for Lean Six Sigma (LSS) in quality 4.0. International Journal of Global Business and Competitiveness, 16(1), 1-14. https://doi.org/10.1007/s42943-020-00018-0

Yadav, S., Garg, D., \& Luthra, S. (2020). Development of IoT based data-driven agriculture supply chain performance measurement framework. Journal of Enterprise Information Management. https://doi.org/10.1108/JEIM-11-2019-0369

Yang, J., Xie, H., Yu, G., \& Liu, M. (2019). Turning responsible purchasing and supply into supply chain responsiveness. Industrial Management and Data Systems. https://doi.org/10.1108/ IMDS-01-2019-0029

Yu, W., Chavez, R., Jacobs, M. A., \& Feng, M. (2018). Data-driven supply chain capabilities and performance: A resource-based view. Transportation Research Part E: Logistics and Transportation Review. https://doi.org/10.1016/j.tre.2017.04.002

Zhu, X., Mukhopadhyay, S. K., \& Kurata, H. (2012). A review of RFID technology and its managerial applications in different industries. Journal of Engineering and Technology Management, 29(1), 152167. https://doi.org/10.1016/j.jengtecman.2011.09.011

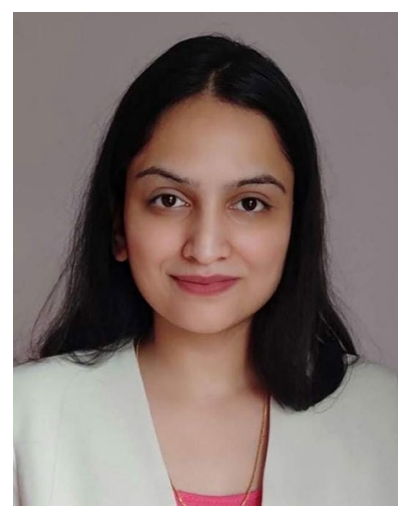

Chetna Chauhan is an assistant professor at FORE School of Management, New Delhi in Quantitative Techniques and Operations Management area. She has completed her doctorate from Indian Institute of Management, Rohtak, India. Her research interests include Industry 4.0 and Internet of Things (IoT), green supply chain management, circular economy and supply chain resilience.

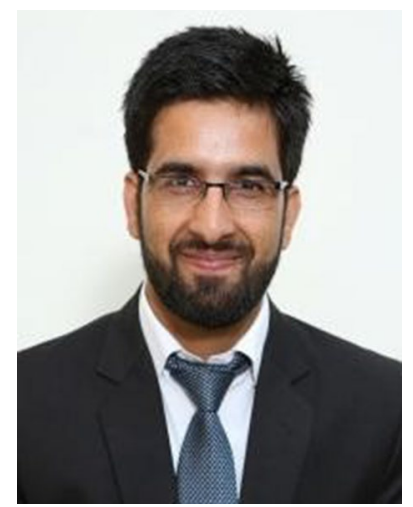

Manzoor UI Akram is a lecturer at O. P. Jindal Global University in Strategy area. His research interests include family firm innovation, technology management and social entrepreneurship.

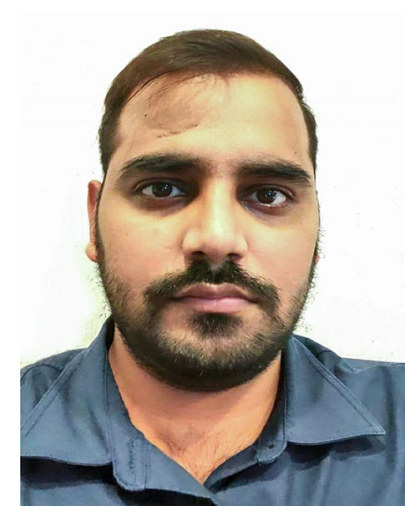

Diptanshu Gaur is a doctoral candidate in the area of economics and public policy at Indian Institute of Management Rohtak. His research interests include governmental policy analysis, corporate strategy, financial markets, and educational inequalities. 